\title{
CARTA DE ERODIBILIDADE DA FOLHA DE COSMÓPOLIS, SÃO PAULO AUXÍLIO AO GERENCIAMENTO DO MEIO FÍSICO
}

\author{
Gustavo Aristides Gomes GRUBER \\ José Roberto RODRIGUES
}

\section{RESUMO}

\begin{abstract}
A Cartografia Geotécnica constitui-se em importante ferramenta nos projetos sócio-econômicos que visam ao estabelecimento e gerenciamento da ocupação ordenada do meio físico. Como um dos produtos da Cartografia Geotécnica, a Carta de Erodibilidade define diferentes unidades homogêneas dos terrenos com base na avaliação de atributos que condicionam a suscetibilidade à erosão. Os trabalhos de mapeamento foram realizados na escala 1:50.000, na região compreendida pela Folha de Cosmópolis, no nordeste do Estado de São Paulo.
\end{abstract}

\section{ABSTRACT}

Engineering Geological mapping is an important tool for the planning and managing land occupation. The susceptibility of the terrain to erosion process is evaluated in engineering geological mapping by means of a Soil Map. This map defines homogeneous land units based on some related aspects (attributes) that influence soil erosion and on the qualitative or quantitative valuation of these attributes. This paper presents the methodology used and the Soil Erosion Map obtained for the Cosmópolis region, northeastern part of the state of São Paulo.

\section{INTRODUÇÃO}

Com o objetivo de proporcionar à sociedade um instrumento de gestão na identificação dos problemas inerentes ao uso e ocupação do solo, a Cartografia Geotécnica constitui-se num processo que propicia um melhor conhecimento dos condicionantes do meio físico.

A suscetibilidade à erosão consiste num importante fator condicionante na utilização dos terrenos, principalmente em obras de engenharia civil e na agropecuária. A Carta de Erodibilidade, objetivo deste trabalho, representa o produto final do cruzamento de atributos influentes na suscetibilidade à erosão dos terrenos. Elaborada na escala 1:50.000, tendo como base cartográfica o mapa topográfico da Folha de Cosmópolis/SP (IBGE, 1974), constitui-se num dos produtos finais da Dissertação de Mestrado (GRUBER, 1993) desenvolvida na Escola de Engenharia de São Carlos - USP.

A área mapeada, com uma extensão de aproximadamente $712 \mathrm{~km}^{2}$, localiza-se na porção nordeste do Estado de São Paulo (FIG. 1) e engloba em seus limites áreas parciais de dez municípios. Os dois com maior representatividade em área são Artur Nogueira e Cosmópolis e possuem suas sedes localizadas na Folha estudada, sendo que os demais ocupam $44,6 \%$.
Tendo como base a proposta metodológica de ZUQUETTE (1987), concebida principalmente para trabalhos em escalas regionais e semi-detalhadas, foram utilizados - para análise e cruzamentos - os seguintes atributos intervenientes na suscetibilidade à erosão: materiais inconsolidados (textura), fator de erodibilidade (Ko - WISCHMEIER \& SMITH, 1978), geomorfologia (declividade, forma e extensão das encostas), uso e ocupação do solo (cobertura vegetal original, agropecuária, obras de engenharia civil e erosão em sulcos).

\section{CARACTERIZAÇÃO DO MEIO FÍSICO DA ÁREA DE ESTUDO}

O estudo da geologia da Folha de Cosmópolis foi conduzido de forma a obter dois tipos de mapas geológicos básicos: o do substrato rochoso, que inclui os diferentes tipos litológicos existentes de idades anteriores ao cenozóico, e o de materiais inconsolidados cenozóicos, residuais ou retrabalhados.

Situada na borda leste da Bacia do Paraná, a área estudada apresenta rochas do Embasamento Cristalino (granitos leucocráticos com granulação média a grossa) como o tipo litológico mais antigo. Sobrepostas a estas são encontradas 


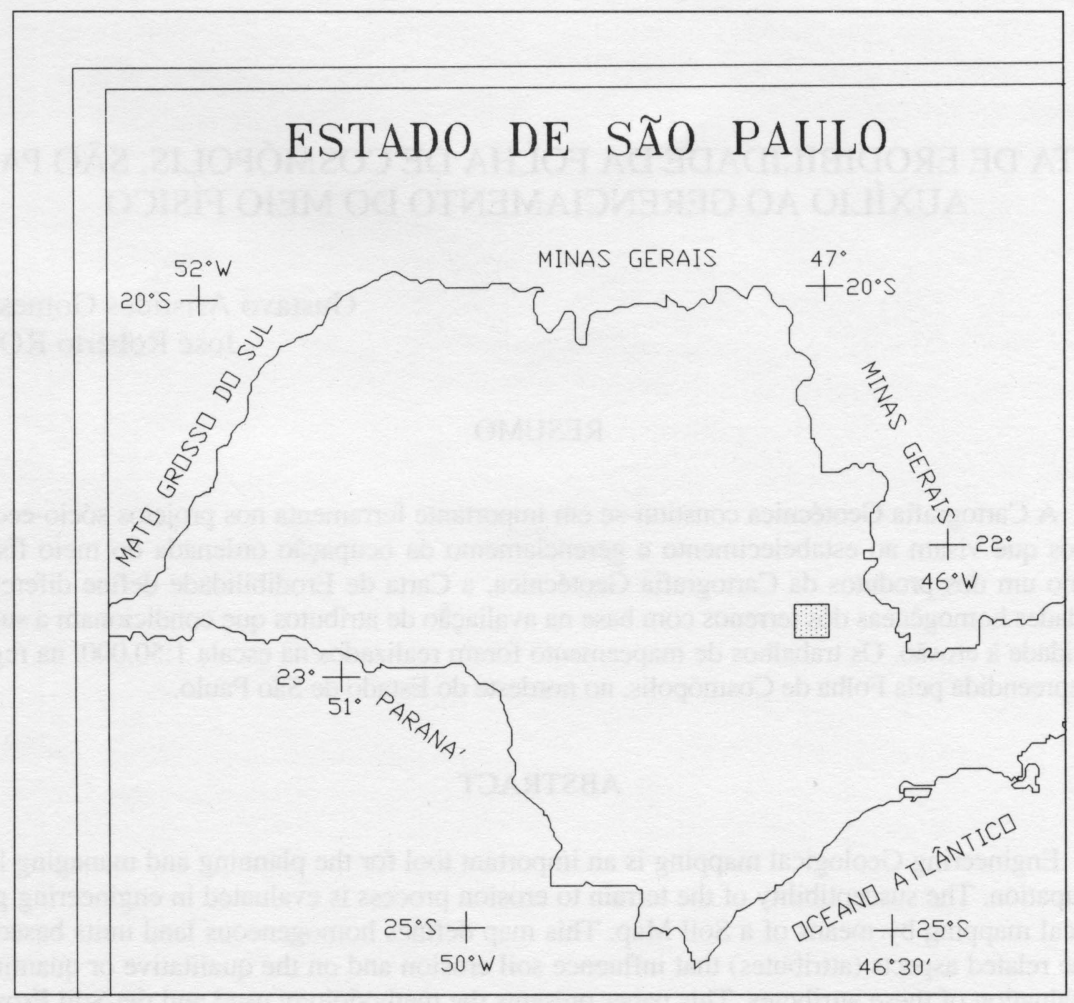

FIGURA 1 - Localização da Folha de Cosmópolis - SF. 23-Y-A-V-2.

rochas do Subgrupo Itararé, subdividido em cinco unidades: Unidade 1 - Arenitos, Unidade 2 - Siltitos, Unidade 3 - Diamictitos, Unidade 4 - Argilitos e Unidade 5 - Intercalações de Arenito/Siltito/Argilito. Distribuídos aleatoriamente por toda a Folha, os corpos de rochas intrusivas (soleiras e diques) são constituídos por diabásios com granulação fina a média.

O procedimento de identificação e seleção dos diversos tipos de materiais inconsolidados (cenozóicos) teve como fonte de informação aquelas obtidas da interpretação de: fotografias aéreas; poços profundos; sondagens à percussão; mapas geológicos, pedológicos e topográficos; caminhamentos de campo e ensaios existentes e produzidos. Como critérios básicos na separação das unidades, foram utilizados a textura dos materiais e o caráter genético, em função de proporcionar uma maior homogeneidade e representatividade dos dados, frente às demais classificações (HRB, SUCS, MCT), que não se mostraram adequadas na elaboração das unidades (GRUBER, 1993). Os materiais inconsolidados foram divididos em Materiais Retrabalhados, desenvolvidos a partir de rochas não imediatamente inferiores, com diferentes graus de retrabalhamento e Materiais Residuais resultantes da alteração in situ das rochas do substrato rochoso. Os
Materiais Retrabalhados foram subdivididos em Material Arenoso, Material Argiloso e Material Aluvionar. Os dois primeiros foram classificados a partir da fração granulométrica dominante de cada amostra analisada. Para os Materiais Residuais procedeu-se à subdivisão em Material Residual do Embasamento Cristalino, Material Residual do Subgrupo Itararé (Unidade 1 Arenitos, Unidade 2 - Siltitos, Unidade 3 Diamictitos, Unidade 4 - Argilitos e Unidade 5 Intercalações de Arenito/Siltito/Argilito) e Material Residual das Intrusivas Básicas (FIG. 2). As características físicas obtidas desses materiais estão relacionadas na tabela 1. Uma pequena porcentagem de amostras possui duas ou mais frações granulométricas com quantidades aproximadas. Nestes casos a classificação da amostra numa determinada unidade sofreu influência, principalmente, do caráter genético. Como importante fonte de informações, os mapas pedológicos contribuem em diversas etapas na realização da Cartografia Geotécnica, em especial na aquisição e interpretação das características físicas, químicas e genéticas dos materiais. O principal mapa pedológico utilizado foi o trabalho de OLIVEIRA et al. (1979). 


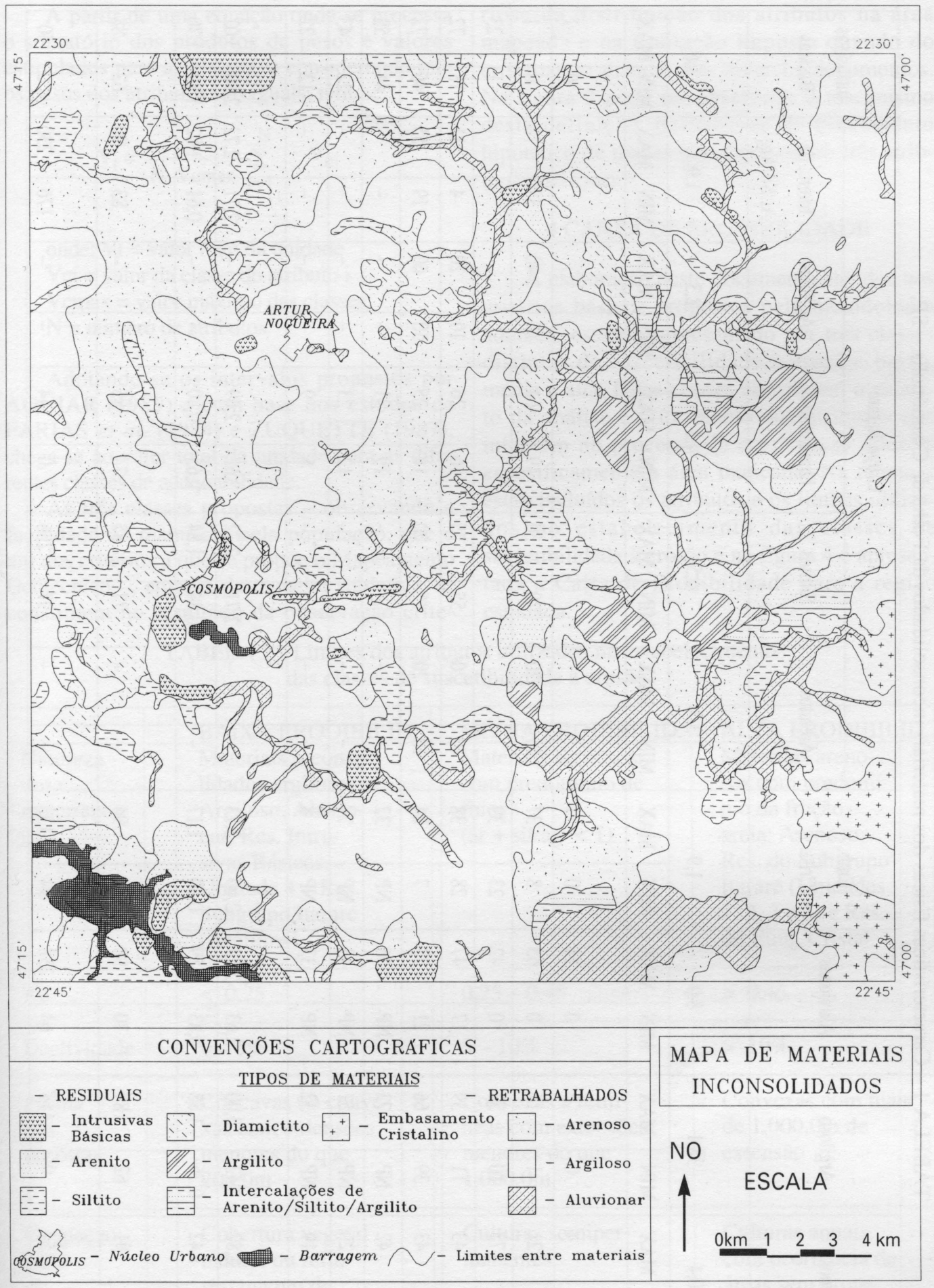

FIGURA 2 - Mapa de materiais inconsolidados - Modificado de GRUBER, 1993.

\section{DEFINIÇÃO DAS UNIDADES HOMOGÊNEAS DE UMA CARTA INTERPRETATIVA}

$O$ principio da definição das unidades homogêneas (ZUQUETTE, 1887 e FARIA et $a l ., 1984)$ se resume na superposição de atributos com mesmo peso e na atribuição de valores subjetivos $(0,1$ e 2$)$ para as classes que compõem os atributos e que representam seu grau de influência na elaboração da carta. 
TABELA 1 - Características físicas dos materiais inconsolidados da Folha de Cosmópolis - SP.

\begin{tabular}{|c|c|c|c|c|c|c|c|c|c|c|c|c|c|c|c|c|c|c|c|c|c|c|}
\hline \multirow{2}{*}{\multicolumn{3}{|c|}{ UNIDADES }} & \multirow{2}{*}{\multicolumn{2}{|c|}{ Arenoso }} & \multirow{2}{*}{\multicolumn{2}{|c|}{ Argiloso }} & \multirow{2}{*}{\multicolumn{2}{|c|}{ Aluvionar }} & \multirow{2}{*}{\multicolumn{2}{|c|}{$\begin{array}{l}\text { Emb. } \\
\text { Crist. }\end{array}$}} & \multicolumn{10}{|c|}{ Grupo Itararé } & \multirow{2}{*}{\multicolumn{2}{|c|}{$\begin{array}{c}\text { Intrusivas } \\
\text { Básicas }\end{array}$}} \\
\hline & & & & & & & & & & & \multicolumn{2}{|c|}{ Arenitos } & \multicolumn{2}{|c|}{ Siltitos } & \multicolumn{2}{|c|}{ Diamictitos } & \multicolumn{2}{|c|}{ Argilitos } & \multicolumn{2}{|c|}{$\begin{array}{l}\text { Interc. de } \\
\text { Ar/Sil/Arg }\end{array}$} & & \\
\hline \multicolumn{3}{|c|}{$\begin{array}{l}\text { \% de área ocupada } \\
\text { na Folha }\end{array}$} & \multicolumn{2}{|c|}{30,4} & \multicolumn{2}{|c|}{38,1} & \multicolumn{2}{|c|}{8,0} & \multicolumn{2}{|c|}{1,9} & \multicolumn{2}{|c|}{3,7} & \multicolumn{2}{|c|}{6,5} & \multicolumn{2}{|c|}{4,5} & \multicolumn{2}{|c|}{2,3} & \multicolumn{2}{|c|}{1,9} & \multicolumn{2}{|c|}{1,6} \\
\hline \multicolumn{3}{|c|}{ VALORES OBTIDOS } & MIN & MAX & MIN & MAX & MIN & MAX & MIN & MAX & MIN & MAX & MIN & MAX & MIN & MAX & MIN & MAX & MIN & MAX & MIN & MAX \\
\hline \multirow{5}{*}{ 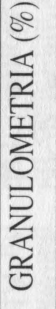 } & \multirow{3}{*}{ 䇋 } & Grossa & 0 & 4 & 0 & 3 & 0 & 11 & 0 & 1 & & & & & & & & & & & 0 & 1 \\
\hline & & Média & 1 & 21 & 1 & 16 & 0 & 65 & 8 & 37 & 55 & 70 & 20 & 30 & 49 & 64 & 25 & 40 & 38 & 70 & 0 & 1 \\
\hline & & Fina & 23 & 73 & 10 & 37 & 0 & 42 & 23 & 39 & & & & & & & & & & & 1 & 23 \\
\hline & \multicolumn{2}{|c|}{ Silte } & 11 & 43 & 11 & 39 & 17 & 47 & 28 & 38 & 10 & 20 & 55 & 75 & 16 & 26 & 10 & 20 & 4 & 11 & 18 & 72 \\
\hline & \multicolumn{2}{|c|}{ Argila } & 13 & 43 & 39 & 66 & 21 & 73 & 7 & 24 & 10 & 20 & 15 & 20 & 18 & 25 & 50 & 60 & 19 & 55 & 46 & 72 \\
\hline \multicolumn{3}{|c|}{$\operatorname{LL}(\%)$} & NP & 42 & NP & 73 & NP & 76 & NP & 32 & - & - & - & - & 19 & 31 & - & - & - & - & 44 & 58 \\
\hline \multicolumn{3}{|c|}{$\mathrm{LP}(\%)$} & NP & 29 & NP & 51 & NP & 43 & NP & 24 & - & - & - & - & 12 & 23 & - & - & - & - & 22 & 43 \\
\hline $\operatorname{IP}(\%$ & & & $\mathrm{NP}$ & 19 & NP & 32 & NP & 33 & NP & 8 & - & - & - & - & 8 & 9 & - & - & - & - & 12 & 22 \\
\hline $\begin{array}{l}\text { M. E } \\
\text { dos S }\end{array}$ & spec & $\left.\mathrm{g} / \mathrm{cm}^{3}\right)$ & 2,59 & 2,82 & 2,43 & 3,00 & 2,63 & 2,73 & 2,60 & 2,73 & - & - & 2,71 & 2,72 & 2,62 & 2,69 & - & - & 2,71 & 2,72 & 2,80 & 3,07 \\
\hline Índic & e de & zios $(\%)$ & 0,58 & 1,42 & 0,76 & 1,88 & 0,83 & 1,59 & 0,50 & 1,17 & - & - & 0,84 & 1,84 & 0,65 & 0,80 & - & - & 0,61 & 1,02 & 1,19 & 1,70 \\
\hline $\begin{array}{l}\text { Grau } \\
\text { Com }\end{array}$ & pact: & $(\%)$ & 64 & 91 & 62 & 89 & 70 & 98 & 74 & 94 & - & - & 77 & 85 & 74 & 85 & - & - & 83 & 90 & 62 & 88 \\
\hline $\begin{array}{l}\text { Perd } \\
\text { por i }\end{array}$ & $\begin{array}{l}\text { de } \\
\text { mers }\end{array}$ & & 0 & 154 & 0 & 114 & 64 & 238 & 94 & 138 & - & - & 97 & 266 & 0 & 144 & - & - & 176 & 230 & 0 & 50 \\
\hline
\end{tabular}


A partir de uma equação onde se processa o somatório dos produtos de pesos e valores estipulados para as classes, e considerando que os pesos dos atributos são iguais, têm-se:

$$
V_{t}=\frac{1}{N \cdot V c m a x} \cdot \sum_{i=1}^{N} V_{c i}
$$

onde: $\mathrm{Vt}=$ valor total da unidade Vci $=$ valor da classe do atributo $\mathrm{i}$ $\mathrm{V} c \max =$ valor máximo das classes $\mathrm{N}=$ número de atributos

Adotando-se os intervalos propostos por AGUIAR (1989) e com base nos estudos de FARIAS et al. (1984) e ZUQUETTE (1987), chega-se ao valor total da unidade para as diferentes classes de adequabilidade.

As três classes propostas - observando a facilidade de manuseio pela população, que é um dos critérios a que se propõe o Mapeamento Geotécnico -, embora de maneira subjetiva, se constituem no resultado da observação crite- riosa da distribuição dos atributos na área mapeada e na limitação imposta quando do cruzamento manual dos diversos documentos. $\mathrm{Na}$ figura 3 pode ser observado o mecanismo desta definição, partindo-se do cruzamento hipotético de mapas que representam três atributos quaisquer.

\section{CARTA DE ERODIBILIDADE}

A elaboração deste documento atendeu aos critérios básicos propostos pela metodologia adotada, estando representado por três classes distintas de suscetibilidade à erosão: baixa, média e alta. Estas classes constituem o produto da análise e cruzamento dos atributos que intervêm no processo de erosão e se referem especificamente à área mapeada. Na tabela 2 estão incluídos os atributos e os limites utilizados no estabelecimento das classes de suscetibilidade à erosão e na figura 4 é apresentada a Carta de Erodibilidade para a região estudada.

TABELA 2 - Limites dos atributos utilizados no estabelecimento das classes de suscetibilidade à erosão.

\begin{tabular}{|c|c|c|c|}
\hline & BAIXA ERODIBILID. & MÉDIA ERODIBILID. & ALTA ERODIBILID \\
\hline $\begin{array}{l}\text { Natureza } \\
\text { dos } \\
\text { materiais }\end{array}$ & $\begin{array}{l}\text { Materiais inconso- } \\
\text { lidados argilosos: } \\
\text { Argiloso, Aluvio- } \\
\text { nar, Res. Intru- } \\
\text { sivas Básicas, } \\
\text { Unidade } 4 \text { - Res. } \\
\text { Subgrupo Itararé } \\
\text { (Argilitos) }\end{array}$ & $\begin{array}{l}\text { Materiais arenosos } \\
\text { com predomínio de } \\
\text { finos } \\
(\text { ar }+ \text { sil/ag }<1)\end{array}$ & $\begin{array}{l}\text { Materiais areno- } \\
\text { sos com predomí- } \\
\text { nio da fração } \\
\text { areia: Arenoso, } \\
\text { Res. do Subgrupo } \\
\text { Itararé (Unidades } \\
\text { 1, 2, 3 e 5) e Res. } \\
\text { do Emb. Cristal. }\end{array}$ \\
\hline Ko & $<0,25$ & $0,25-0,45$ & $>0,45$ \\
\hline Declividade & $0-5 \%$ & $5-10 \%$ & $>10 \%$ \\
\hline $\begin{array}{l}\text { Forma } \\
\text { das } \\
\text { encostas }\end{array}$ & $\begin{array}{l}\text { Côncavas ou conve- } \\
\text { xas com extensões } \\
\text { menores do que } \\
200,0 \mathrm{~m}\end{array}$ & $\begin{array}{l}\text { Convexas a retilí- } \\
\text { neas com extensões } \\
\text { menores do que } \\
1.000,0 \mathrm{~m}\end{array}$ & $\begin{array}{l}\text { Convexas com mais } \\
\text { de } 1.000,0 \mathrm{~m} \text { de } \\
\text { extensão }\end{array}$ \\
\hline $\begin{array}{l}\text { Ocupação } \\
\text { atual } \\
\text { ou } \\
\text { prevista }\end{array}$ & $\begin{array}{l}\text { Cobertura vegetal } \\
\text { natural ou reflo- } \\
\text { restamento de } \\
\text { grande porte }\end{array}$ & $\begin{array}{l}\text { Culturas semiper- } \\
\text { manentes }\end{array}$ & $\begin{array}{l}\text { Culturas anuais, } \\
\text { com ocorrência de } \\
\text { áreas sem prote- } \\
\text { ção vegetal e com } \\
\text { ocupação urbana } \\
\text { desordenada }\end{array}$ \\
\hline $\begin{array}{l}\text { Erosão } \\
\text { em sulcos }\end{array}$ & Sem vestígios & - & $\begin{array}{l}\text { Apresenta vestí- } \\
\text { gios }\end{array}$ \\
\hline
\end{tabular}

Ko - fator de erodibilidade (WISCHMEIER \& SMITH, 1978) 


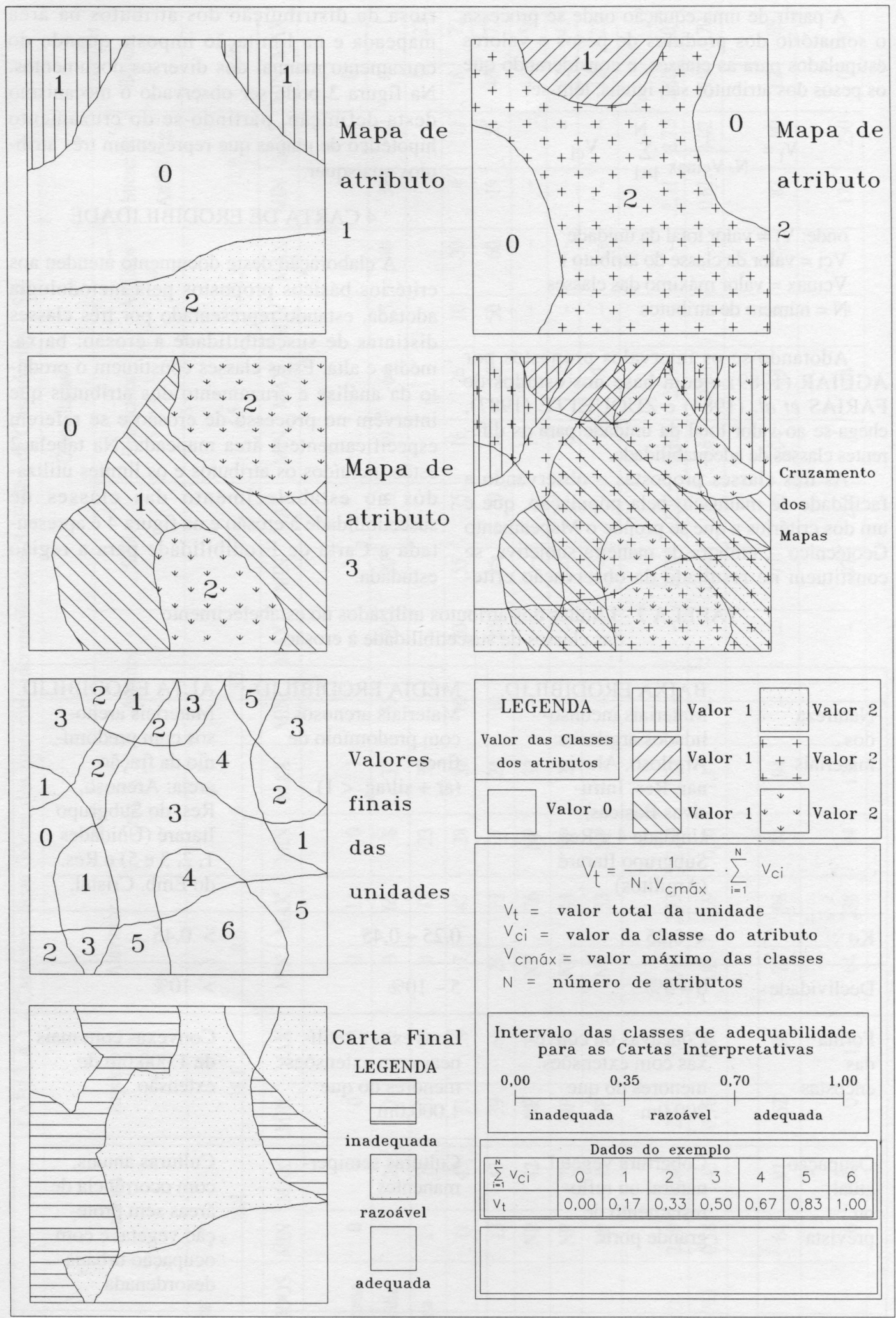

FIGURA 3 - Definição das unidades (GRUBER, 1993). 


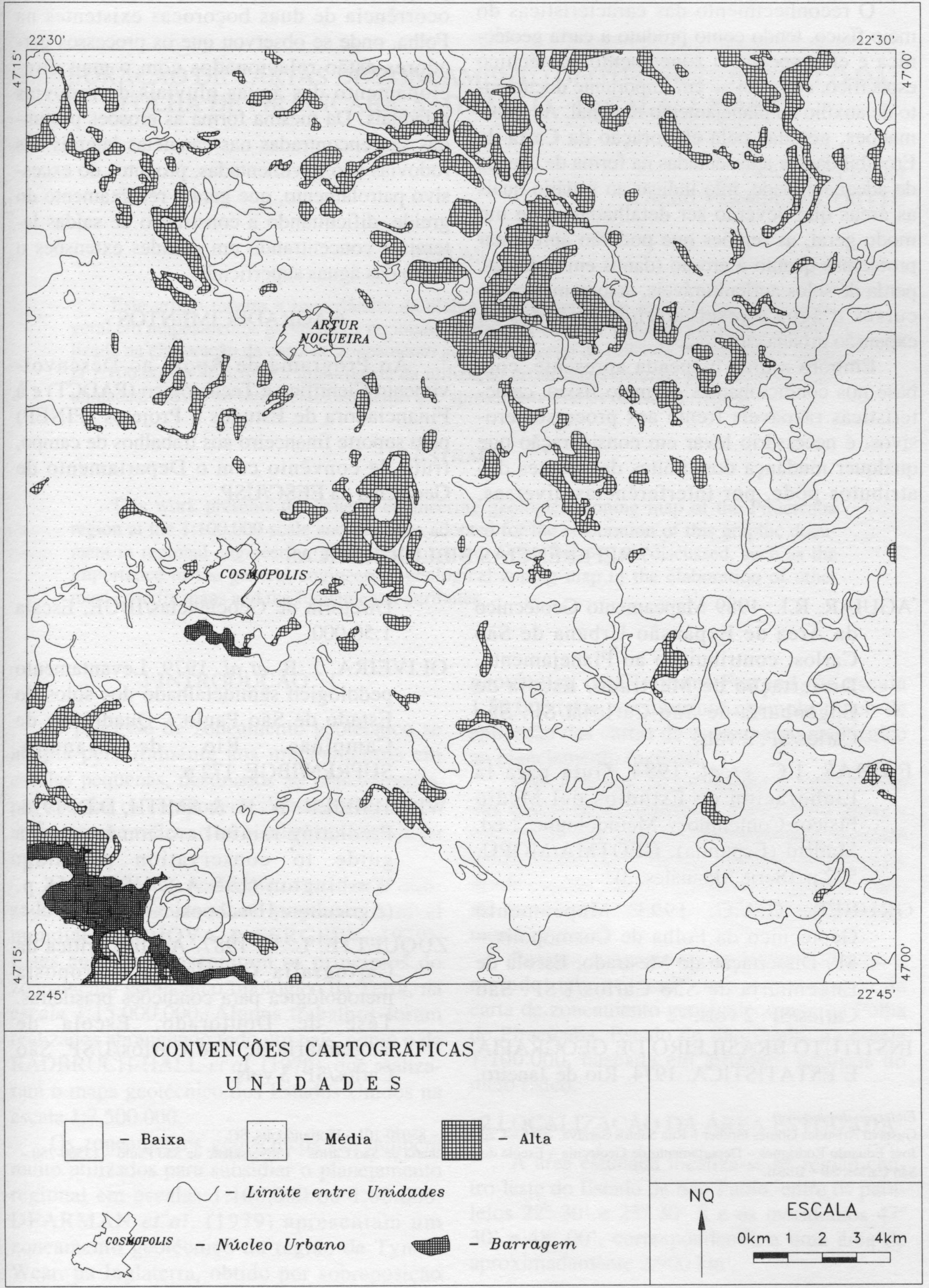

FIGURA 4 - Carta de erodibilidade - Modificado de GRUBER, 1993. 


\section{CONSIDERAÇÕES FINAIS}

O reconhecimento das características do meio físico, tendo como produto a carta geotécnica e em especial o zoneamento geotécnico específico, constitui-se em importante documento de auxílio ao planejamento regional. As informações, geradas pela elaboração da Carta de Erodibilidade e apresentadas na forma de classes de adequabilidade, irão indicar ao usuário quais as áreas que deverão ser detalhadas e, de um modo geral, as regiões que poderão apresentar problemas quanto à erosão (danos em rodovias, perda de solos agriculturáveis, assoreamentos de cursos d'água e reservatórios, cuidados na expansão urbana etc).

Embora a área mapeada apresente, com base nos condicionantes do meio físico, características razoáveis frente aos processos erosivos, é necessário levar em consideração que qualquer mudança dos limites das classes dos atributos pode, por interferências diversas, desestabilizar ou estabilizar uma determinada porção do terreno. Isto pode ser constatado na ocorrência de duas boçorocas existentes na Folha, onde se observou que os processos geradores estão relacionados com o mau direcionamento das águas pluviais de rodovias estaduais. Da mesma forma as erosões profundas são encontradas nas canaletas laterais das rodovias não pavimentadas, produtos do excessivo patrolamento, que gera o rebaixamento do greide, dificultando a construção de saídas laterais e concentrando em grandes extensões o fluxo das águas superficiais

\section{AGRADECIMENTOS}

Ao Programa de Apoio ao Desenvolvimento Científico e Tecnológico (PADCT) e à Financiadora de Estudos e Projetos (FINEP) pelo suporte financeiro aos trabalhos de campo, fruto de convênio com o Departamento de Geotecnia da EESC/USP.

\section{REFERÊNCIAS BIBLIOGRÁFICAS}

AGUIAR, R.L. 1989 Mapeamento Geotécnico da Área de Expansão Urbana de São Carlos: contribuição ao Planejamento. Dissertação de Mestrado, Escola de Engenharia de São Carlos/USP. São Carlos/SP, 2 vols.

FARIAS, I.C. et al. 1984. Guia para la Elaboracion de Estudios del Medio Fisico: Contenido y Metodologia. 2 ed. Madrid (Espanha), CEOTMA/MOPU, 572 p. (Serie Manuales, 3).

GRUBER, G.A.G. 1993. Mapeamento Geotécnico da Folha de Cosmópolis SP. Dissertação de Mestrado, Escola de Engenharia de São Carlos/USP. São Carlos/SP. 2 vols.

INSTITUTO BRASILEIRO DE GEOGRAFIA E ESTATÍSTICA. 1974. Rio de Janeiro,
Diretoria de Geociências/IBGE, Escala 1:50.000.

OLIVEIRA, J. B. et al. 1979. Levantamento pedológico semidetalhado dos solos do Estado de São Paulo - Quadrícula de Campinas. Rio de Janeiro, SUPREN/IBGE, $172 \mathrm{p}$.

WISCHMEIER, W. H. \& SMITH, D.D. 1978. Predicting rainfall erosion losses - a guide to conservation planning. Washington (U.S.A.), USDA, 58 p. (Agriculture Handbook, 537).

ZUQUETTE, L. V. 1987. Análise crítica da Cartografia Geotécnica e proposta metodológica para condições brasileiras. Tese de Doutorado, Escola de Engenharia de São Carlos/USP. São Carlos/SP, 3 vols.

Gustavo Aristides Gomes Gruber - Rua Santos Saraiva, 2011 - Capoeiras - 88070-101 - Florianópolis, SC.

José Eduardo Rodrigues - Departamento de Geotecnia - Escola de Engenharia de São Carlos - Universidade de São Paulo - $13560-250$ -

São Carlos, SP - Brasil. 